\title{
Phenotype-genotype correlation in Jewish patients suffering from familial Mediterranean fever (FMF)
}

\author{
$M$ arie D ewalle ${ }^{1}$, Cécile Domingo $^{1}, M$ ichel R ozenbaum ${ }^{2}, E$ Idad B en-Chétrit ${ }^{3}, D$ aniel \\ Cattan ${ }^{4}$, A lain Bernot ${ }^{5}$, Christiane D ross ${ }^{1}$, M adeleine D upont $^{1}$, Cécile N otarnicola ${ }^{1}$, \\ M icha Levy ${ }^{3}$, Itzhak R osner ${ }^{2}$, Jacques D emaille ${ }^{1}$ and I sabelle Touitou ${ }^{1}$
}

${ }^{1} \mathrm{H}$ ôpital A de Villeneuve, Montpellier, France

${ }^{2} \mathrm{~B}$ nai Zion M edical Center, $\mathrm{H}$ aifa, Israel

${ }^{3} \mathrm{H}$ adassah $\mathrm{H}$ ospital, Jerusalem, I srael

${ }^{4} \mathrm{H}$ ôpital de Villeneuve Saint $\mathrm{G}$ eorges, France

${ }^{5}$ CNS, E vry, France

\begin{abstract}
Familial Mediterranean Fever is one of the most frequent recessive disease in non-Ashkenazi Jews. The gene responsible for the disease (MEFV) has very recently been identified. The M694V ('MED') mutation was found in about $80 \%$ of the FMF Jewish (Iraqi and North African) chromosomes. To see if the presence of this mutation could be correlated with particular traits of the disease, we examined a number of clinical features in a panel of 109 Jewish FMF patients with 0,1 or 2 MED mutations. We showed that homozygosity for this mutation was significantly associated with a more severe form of the disease. In homozygous patients, the disease started earlier (mean age $6.4+/-5$ vs $13.6+/-8.9$ ) and both arthritis and pleuritis were twice as frequent as in patients with one or no $M 694 \mathrm{~V}$ mutation. Moreover, $3 / 3$ patients with amyloidosis displayed two MED mutations. No association was found with fever, peritonitis, response to colchicine and erysipeloid eruption. The present result strongly suggests the potential prognostic value of the presence of this mutation.
\end{abstract}

Keywords: FMF; Jews; M694V mutation; prognosis

\section{Introduction}

The name of Familial Mediterranean Fever (FMF) has been given to this disease because it is a hereditary

Correspondence: D r I sabelle Touitou, L aboratoire de génétique moléculaire et chromosomique, $\mathrm{H}$ ôpital $\mathrm{A}$ de Villeneuve, 371, Au du doyen Giraud, 34275 M ontpellier CEDEX 5, France. Tel: (33) 4673358 59; Fax (33) 4673358 62; E mail: touitou@vega.crbm.cnrs-mop.fr

Received 5 September 1997; revised 5 November 1997; accepted 18 November 1997 inflammatory disorder particularly common in populations from Mediterranean ancestry: Jews, A rmenians, Turks and A rabs. ${ }^{1}$ A ffected patients may manifest various forms of the disease from mild symptomatology to severe acute attacks and articular or renal complications. ${ }^{2}$ The biological basis of FM F is still unknown but should shortly be elucidated with the recent identification of the causative gene (ME FV) by our group and an independent consortium. ${ }^{3,4}$ Four conservative mutations clustered in the last exon account for $86 \%$ of the 
MEFV chromosomes. The M 694V mutation is carried by about one third of the A rmenian, Turkish and $A$ rab FM F chromosomes, whereas it is carried by $80 \%$ of the FMF chromosomes in Jews. ${ }^{3,4}$ This mutation is associated with the MED haplotype, ${ }^{5}$ which is identical to the ' $A$ ' haplotype described by the International FM F Consortium. ${ }^{4}$ Since $\mathrm{FMF}$ is usually more severe in J ews from $N$ orth A frica than in other populations, we asked whether this phenotypic particularity could be associated with the high frequency of the MED mutation in this population. We thus documented in detail each of the major FMF clinical features in our affected Jewish individuals and the results were compared to the number of MED mutations they carry. The present study provides evidence that there may be a direct molecular basis for the phenotypic variable expressivity of the disease.

\section{Patients and Methods}

\section{Patients}

The family panel that was included in the present study was composed of $109 \mathrm{FMF}$ non-A shkenazi Jewish patients (93 from North A frica, 10 from Iraq, 2 from E gypt and 4 from Syria). The investigated patients originated from 49 independent pedigrees, 25 harbouring siblings. We observed $27 \%$ discordant phenotypes in siblings. A blind trial was performed as follows. Since the patients had been recruited from a large number of medical centers, they were all reinterviewed by one of the clinicians involved in the study, either directly during a consultation, or by telephone. All clinicians had identical clinical forms including the following information: patient identification, FMF symptomatology which was divided into fever, abdominal, thoracic, articular, skin, renal and miscellaneous manifestations, duration and frequency of the attacks, colchicine dose and effect, associated pathologies, biology when available and genealogy tree. Genetic forms were also designed and filled out with the patient code identifications, and the corresponding alleles for each marker and mutation studied. B oth forms were computed into two separated files related by the patient code using the M icrosoft A ccess 7.0 software.

\section{Mutation Analysis}

The four mutations accounting for $86 \%$ of the FM F chromosomes in various populations ${ }^{3}$ were systematically investigated in the patients. The ARM2 (M 680I) and ARM 3 (V 726A) mutations were PCR amplified using primers 10.1 and $12.2^{3}$ and the alleles were identified following $A$ lu.1 and $\mathrm{H}$ inf1 digestion respectively. The MED and A R A 2 (M 694I) mutations were investigated using primer 12.2 and one of the three allele-specific ( $M, V$ or $I$ ) primers. ${ }^{3}$ When the phase could not be established and only one allele was detected, data were duplicated to ascertain homozygosity. We further co-amplified an ubiquitous gene (abl, forward primer $5^{\prime}$ CCT TCA GCG GCC AGT AGC ATC TGC C 3', backward primer 5' GGA CAC AGG CCC ATG GT. CAC GGA G 3') in each of the three tubes, as an internal control.

\section{Statistical Analysis}

A ge at onset was evaluated using the test (mean comparison). A rthritis, pleuritis and peritonitis were assessed using chi square. The other features were not statistically ascertained since results were superimposable.

\section{Results}

Table 1 depicts the distribution of the M ED mutation in 109 J ewish patients. M ore than half of the patients were found homozygous for the MED mutation in our family panel, whereas only nine patients were compound heterozygotes (2 MED/ARA 2, 6 MED/ARM 3, 1 A RM 3/ARM 2). In view of the small size of the other possible allelic combinations, we tagged all non-MED chromosomes as 'other'. The sex ratio was examined first since higher penetrance was described in males. We found similar genotype distribution and no significant clinical variations between sexes (not shown).

We then considered each of the clinical features described above as a function of the number of MED mutations carried by the FM F patients. There were no significant differences between compound heterozygous individuals and individuals with no MED mutation (not shown). These two groups were therefore pooled. In contrast (Table 2a), age at onset was significantly lower in patients homozygous for the MED mutation with a mean age $6.4+/-5$ as compared to $13.6+/-8.9\left(p<10^{-4}\right)$ in non-homozygous patients. In the 'MED/MED' group more than half of the patients manifested the disease before the age of 5 and penetrance was complete by the age of 30 . Similarly, arthritis and pleuritis were more frequent in patients with two MED mutations ( $p=0,002$ and 0,0002 respectively). Fever, peritonitis, rash and effect of colchicine were not associated with this mutation (Table 2b). The possible association with amyloidosis could not be searched since we had only three patients with this complication in our J ewish family panel. However, it is noteworthy that all these were homozygous for the MED mutation (not shown).

Table 1 Distribution of the MED mutation in $109 \mathrm{~J}$ ewish patients

\begin{tabular}{lll}
\hline & M ales & Females \\
\hline MED/MED & 30 & 30 \\
MED/Othera & 16 & 14 \\
Othera/O thera & 10 & 9 \\
\hline
\end{tabular}

aR efers to $F M F$ chromosomes with either one of the three other mutations (ARM2, ARA 2 and ARM 3) or with still unknown mutation. 
Table 2 FM F clinical features (\%)

(a) A ssociated with homozygosity for the MED mutation

\begin{tabular}{|c|c|c|c|c|c|c|c|c|c|c|}
\hline & \multicolumn{6}{|c|}{$\begin{array}{l}\text { A ge at onset }\left(p<10^{-4}\right) \\
\text { years }\end{array}$} & \multicolumn{2}{|c|}{$\begin{array}{l}\text { Pleuritis } \\
\left(p=2.10^{-4}\right)\end{array}$} & \multicolumn{2}{|c|}{$\begin{array}{l}\text { A rthritis } \\
\left(p=2.10^{-3}\right)\end{array}$} \\
\hline $\begin{array}{l}\mathrm{M} \text { ed/M ed } \\
\mathrm{O} \text { ther }\end{array}$ & $\begin{array}{l}<5 \\
0.51 \\
0.24\end{array}$ & $\begin{array}{l}5-9 \\
0.28 \\
0.14\end{array}$ & $\begin{array}{c}10-14 \\
0.16 \\
0.19\end{array}$ & $\begin{array}{c}15-19 \\
0.03 \\
0.21\end{array}$ & $\begin{array}{c}20-30 \\
0.02 \\
0.17\end{array}$ & $\begin{array}{c}>30 \\
0 \\
0.05\end{array}$ & $\begin{array}{l}\text { Yes } \\
0.78 \\
0.38\end{array}$ & $\begin{array}{l}\text { No } \\
0.22 \\
0.62\end{array}$ & $\begin{array}{l}\text { Y es } \\
0.86 \\
0.57\end{array}$ & $\begin{array}{l}\text { No } \\
0.14 \\
0.43\end{array}$ \\
\hline \multicolumn{11}{|c|}{ (b) Not associated with homozygosity for the MED mutation } \\
\hline & \multicolumn{2}{|l|}{ Fever } & \multicolumn{2}{|c|}{ Peritonitis } & \multicolumn{2}{|c|}{ E rysipelas } & \multicolumn{4}{|c|}{ Response to colchicine } \\
\hline $\begin{array}{l}\text { M ed/M ed } \\
\text { O ther }\end{array}$ & $\begin{array}{l}0.93 \\
0.91\end{array}$ & $\begin{array}{l}0.07 \\
0.09\end{array}$ & $\begin{array}{l}0.97 \\
0.84\end{array}$ & $\begin{array}{l}0.03 \\
0.16\end{array}$ & $\begin{array}{l}0.13 \\
0.14\end{array}$ & $\begin{array}{l}0.87 \\
0.86\end{array}$ & $\begin{array}{l}0.05 \\
0.05\end{array}$ & $\begin{array}{l}0.12 \\
0.11\end{array}$ & $\begin{array}{l}0.23 \\
0.26\end{array}$ & $\begin{array}{l}0.6 \\
0.58\end{array}$ \\
\hline
\end{tabular}

\section{Discussion}

It is well known that among populations affected by FM F, non-A shkenazi Jews are those suffering from the most severe form of the disease. ${ }^{2}$ In particular, acute attacks of arthritis and renal failure are more often seen in J ews than in A rabs, A rmenians and Turks. This work was aimed at establishing whether the presence of the most frequent FMF (M 694V/MED) mutation was associated with any of the main clinical features of the disease in Jews. Since locus homogeneity is demonstrated in a growing panel of independent families, ${ }^{6,7}$ the molecular basis of FM F variable expressivity must be due to either allelic heterogeneity, still unknown modifier genes, epigenetic factors or to combined factors. We show here that patients with 0 or 1 MED mutation disclosed more limited features of the disease (later onset of the disease, less pleuritis, arthralgia or arthritis and probably renal amyloidosis). This observation supports allelic heterogeneity (without excluding other genetic mechanisms) and suggests that the codon 694 is located in a critical functional site of the encoded product (the Marenostrin/Pyrin protein). In favour of this hypothesis, we also found that one Turkish and one A rab kindred with renal complication were homozygous for substitutions occurring within the same codon: a methionine mutation into a valine or an isoleucine, respectively (not shown).

It is still possible that the phenotypic-genotypic correlation demonstrated above is not due to the MED mutation itself. This would mean that at least one modifier gene involved in inflammation is tightly associated with this mutation, which in itself is important to know. To address this question definitely, we are currently focusing our efforts on other populations so as to enlarge our panel of patients with the three other major mutations. Nevertheless, whatever the physiological significance of the association shown here, it has an immediate clinical application. The characterisation of the mutations responsible for the disease conveys information for patient prognosis. The molecular analysis should be extended to all family members since penetrance was found to be $100 \%$ in the MED/MED group.

\section{Acknowledgements}

We are indebted to families and physicians without whom the study would not have been possible. We thank Prs Delpech, Claustres and Weissenbach for fruitful discussion. This work was supported by the A ssociation Française pour la M yopathie, and the Centre Hospitalier de Montpellier.

\section{References}

1 Heller H, Sohar E, Sherf L: Familial M editerranean Fever (FM F). A rch Int M ed 1958; 102: 50-71.

2 Sohar E, G afni J, Pras M, H eller H : Familial M editerranean Fever: A survey of 470 cases and review of the literature. A m J Med 1967; 43: 227-253.

3 The French FM F consortium: A candidate gene for familial M editerranean fever. $\mathrm{N}$ at $\mathrm{G}$ en 1997; 17: 25-31.

4 The International FMF consortium: A ncient missense mutations in a new member of the $\mathrm{R} O \mathrm{R}$ et gene family are likely to cause familial Mediterranean fever. Cell 1997; 90: 797-807.

5 The French FMF Consortium: Evidence for a common founder effect in A rabs, A rmenians, non-A shkenazi Jews and Turks. E ur J H um G enet submitted.

6 Pras E , A ksentijevich I, G ruberg L et al: M apping of a gene causing Familial Mediterranean Fever to the short arm of chromosome 16. New Engl J M ed 1992; 326: 1509-1513.

7 The FMF French consortium: L ocalization of the Familial $M$ editerranean Fever (FMF) gene to a $250 \mathrm{~kb}$ interval in non-A shkenazi Jewish haplotypes. A m J Human Genet 1996; 59: 603-612. 